\title{
FBG Multifunctional pH Sensor - Monitoring the pH Rain in Cultural Heritage
}

\author{
Lorenzo Dinia $^{1}$, Fabio Mangini ${ }^{1,2}$, Marco Muzi $^{1,3}$, Fabrizio Frezza $^{1}$ \\ ${ }^{1}$ Department of Information Engineering, Electronics and Telecommunications, "Sapienza" University of Rome, Rome, Italy. \\ 2 Santa Lucia Foundation, Rome, Italy. \\ ${ }^{3}$ Engineering Departmental Faculty, "Campus-Biomedico" University of Rome, Rome, Italy
}

\section{ABSTRACT}

A new era of pollution requires an important focus on the conservation of archaeological sites and monuments. In the last years great efforts were required to develop various sensors for different tasks. The fiber Bragg grating (FBG) was one of the most studied thanks to the multitude of applications and the surprising performances. An original fiber optic sensor that combines the fiber Bragg gratings with a $\mathrm{pH}$-responsive polymer coating for monitoring the $\mathrm{pH}$ of the rains on critical and prestigious monuments is proposed. The core consists of four different materials, which makes the sensor very innovative and allowing it to reach a high sensitivity. In this study, the setup arrangement of the optical sensor is modeled with COMSOL Multiphysics (Wave Optics Module), based on the FEM (Finite Element Method) solver. Monitoring the $\mathrm{pH}$ of water can be used by experts to predict and control the corrosion phenomenon of specific materials, especially limestone and marble, thus scheduling the timely restoration.

\section{Section: RESEARCH PAPER}

Keywords: Fiber Bragg grating; pH sensor; hydrogel; cultural heritage monitoring; FEM

Citation: Lorenzo Dinia, Fabio Mangini, Marco Muzi, Fabrizio Frezza, FBG Multifunctional pH Sensor - Monitoring the pH Rain in Cultural Heritage, Acta IMEKO, vol. 7, no. 3, article 6, October 2018, identifier: IMEKO-ACTA-07 (2018)-03-6

Section Editor: Sabrina Grassini, Politecnico di Torino, Italy

Received February 28, 2018; In final form September 25, 2018; Published October 2018

Copyright: (C) 2018 IMEKO. This is an open-access article distributed under the terms of the Creative Commons Attribution 3.0 License, which permits unrestricted use, distribution, and reproduction in any medium, provided the original author and source are credited

Corresponding author: Lorenzo Dinia, lorenzo.dinia@uniroma1.it

\section{INTRODUCTION}

During the last decades, there has been a rising interest in the development of sensors based on optical fibers for several applications, including chemical sensing [1]. Over the years, the acid rains damage monuments and other ancient artworks, destroying the historical and cultural heritage of many countries much faster. Acid rains promote the metal and marble corrosion, determining a loss of mechanical strength and compactness, causing a partial dissolution of the materials themselves and ultimately resulting in the destruction of monuments [2] (Figure 1). The sulfates, present in the acid rain, transform the calcium carbonate into gypsum, known as soft sulfate mineral composed of calcium sulfate dehydrate [2]. This phenomenon is very critical in countries like China with the tremendous pollution that started with the fast industrial growth of the past years, which triggered an acceleration in the destruction of buildings and artworks [2]. This has created in the last years an important interest on how to identify the starting point of the damages to prevent them [3]. In the past, optical analysis and analytical techniques have been used to identify the compound responsible for the corrosion and deterioration of the original artworks' material, discovering that the gypsum was always present in samples of deteriorated marble [2]. Moreover, traces of nitrates and sulfates were investigated on marble surfaces' samples. It was discovered that although both sulfates and nitrates are compounds present in the acid rain in significant quantities, the concentration of sulfates on the samples was 20 times bigger than the quantity of nitrates [2]. This result provided a significant indication about the leading responsibility of the sulfates in deteriorating marbles [2].

The problem of the acidification of the air and rains was discussed and addressed many years ago during the Medieval Era, even if it was limited to few compounds mainly released around the cities and to the volcanic eruptions [4]. Acid rain has been detected, during the second half of the nineteenth century, primarily in Europe, East Asia and North America [3]. 


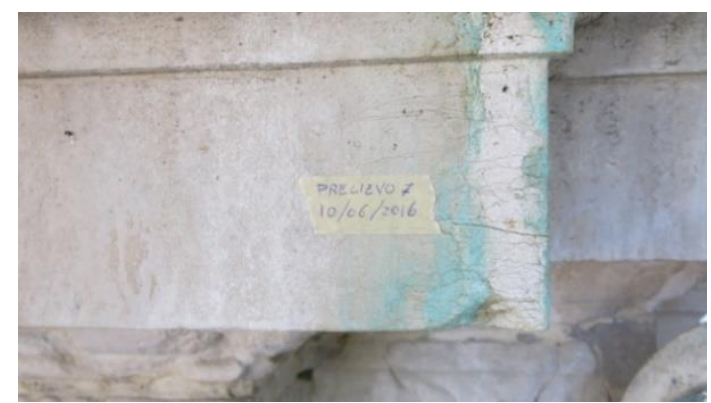

Figure 1. Neptune's Fountain of Giambologna - Bologna, Italy; a portion of stone material stained in a light blue color. The stains are caused by the percolation of the corrosion products of the overlying bronze elements.

The industrial age improved the average life quality of human beings but on the other hand provoked intense atmospheric acid deposition through rain, fog and snow, threatening the environmental stability and the conservation of monuments and artworks [3].

The corrosion of different materials cannot be prevented without continuously monitoring the $\mathrm{pH}$ of the rain. Presently, the catastrophic effects of the polluted rains are addressed merely with restoration after visible damages, such as micro cracks, discoloration and corrosion as seen in Figure 2.

With an innovative monitoring procedure of the water $\mathrm{pH}$, maintenance and restoration programs can easily be set depending on the chemical features of the rains over the years. Monitoring the $\mathrm{pH}$ can also help to forecast the possible damages for the different materials, in order to preserve the original status of the artworks by also using new laser cleaning method to remove the dirt resulting from acid rains [5].

The main enemy of the artworks is the acidity of the rain, [3], [6] that attacks the statues and ancient buildings, causing enormous damages without control. The calcareous building stones are one of the main materials most sensitive to pollutants [7], [8]. Normal rain is not neutral like pure water but is slightly acidic at around $5.6 \mathrm{pH}$ or lower [3], [6]. Industrial areas have registered acidity of the rain below a $\mathrm{pH}$ value of 2.4 [3], [6]. Rainwater becomes weakly acidic because carbon dioxide gas in the atmosphere reacts with water to form carbonic acid. Moreover, the rainwater increases the acidity even more, mixing with sulphur oxide and nitrogen oxide molecules, coming from industrial pollution and automobile exhaust [2], [3], [6]-[8]. The corrosion rate on artworks is much faster in industrialized areas and areas where human activities are more intense [3], [4]. Sandstone, limestone and marble of

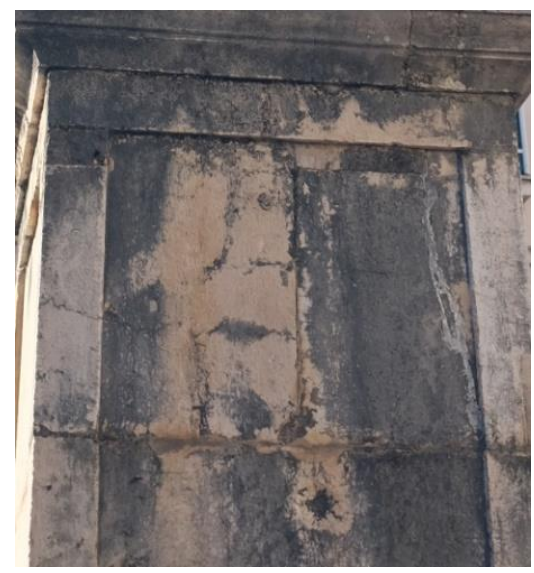

Figure 2. Fountain of the Obelisk of Republic Square - Fondi (LT), Italy. monuments and artworks are affected by acid rain because calcium carbonate, one of the main constituents of these materials, reacts with sulphur, present in dry deposition, and form calcium sulphate [3], [7], [8]. This product is very soluble, and all the acids formed thereby and deposited are washed off the stone's surface with the following rains, damaging the world's cultural heritage, ancient monuments, historic buildings, sculptures, and paintings [3]. Therefore, acid rains are responsible for the loss of original features and the impairment of monuments and artworks [3], [7].

The different sources of $\mathrm{SO}_{2}$ emissions are the burning of coal and petroleum, several industrial processes, the smelting of iron and some other metals, the manufacturing of sulphuric acid, and all the activities related to the acid concentrators in the petroleum industries [3], [7], [8]. Surely the emission of $\mathrm{NO}_{\mathrm{x}}$ compared to $\mathrm{SO}_{2}$ are much less but still harmful in making the rain even more acidic [3], [7], [8]. There are natural sources of nitric oxide, but men contribute heavily with power plants, vehicle exhausts and industrial processes too [3], [7], [8].

In this scenario, in which the sustainability is one of the main objectives of the industrialized countries, monitoring the damages caused by the pollution is necessary for improving the quality of human life, reducing diseases as well as for economic reasons.

Fiber Bragg grating (FBG) sensors coated with $\mathrm{pH}$-sensitive hydrogel have been studied through a simulation, which showed that they can provide a linear response in the $\mathrm{pH}$ range of 5 to 7 with a sensitivity of $0.164 \mathrm{~nm} / \mathrm{pH}$ unit [9], [10]. Optical $\mathrm{pH}$ sensors have advantages compared to the conventional ones, being free from electromagnetic interference, having wide bandwidth, being open to miniaturization, real-time measurement and remote sensing [11]-[13].

The outstanding innovation of this paper is to monitor point by point the $\mathrm{pH}$ of the water in artworks in real-time with a high sensitivity. The actual $\mathrm{pH}$ of the water, resulting from the mixing of calcium carbonate and calcium-based compounds, coming from limestone and marble, with acid rain can be discovered.

This technique allows to monitor small and critical areas like an elbow or an inner thigh of a statue.

The $\mathrm{pH}$ sensor suffers from some limitations due to temperature and bending cross-sensitivities [14]-[17] that will be assumed to be constant and negligible, respectively. This assumption does not seem to be too problematic, as there is a wide variety of compensation techniques for such variables. The accuracy of the sensor is also affected by the multiple resonance peaks and the vast transmission resonance [15]. One of the main advantages of the fiber Bragg grating coated with hydrogel is that the sensed information is encoded directly into wavelength, providing an outcome independent of the intensity of the input light and the loss along the optical system [15].

The device can be split into two sensors, one using a $\mathrm{pH}$-sensitive polymer with an acidic group and the other with a polymer with a basic group. In contact with certain $\mathrm{pH}$ values, the polymers acquire a charge, become ionized and cause a modification of the length of the fiber Bragg grating. The configuration of the device could be composed of two fiber Bragg grating sensors to detect both acidic and basic variations.

A further strength of the device is its size. The developed sensor has a length of $10 \mathrm{~mm}$. The small size allows the sensor to be located on almost unreachable artwork elements for $\mathrm{pH}$ monitoring. 


\section{MATERIALS AND METHODS}

The optical fiber sensor is composed by layers of alternating materials with different refractive indices as shown in the schematic in Figure 3. Each layer boundary causes a partial reflection of the incident optical wave. The $\mathrm{pH}$-responsive polymers respond to the changes in the $\mathrm{pH}$ of the surrounding water by having a volumetric variation. The expansion of the polymer coating causes a strain on the fiber, modifying the Bragg grating period that results in a shift in resonant Bragg wavelength, and thus in the sensor response. Peak reflectance is achieved with a design wavelength $\lambda_{0}$ when the configuration of Bragg grating provides constructive interference between reflections. This is reached when the Bragg condition is satisfied:

$\lambda_{0}=2 n_{e f f} \Lambda$,

where $n_{\text {eff }}$ is the effective refractive index of the optical fiber and $\Lambda$ is the grating period. The Bragg wavelength is set to 550 $\mathrm{nm}$, because it is the average wavelength of the visible spectrum and because it minimizes the loss of the light in the fiber. Achieving the Bragg condition requires layer thicknesses of:

$$
t_{i}=\lambda_{0} / 4 n_{i}
$$

where $n_{i}$ is the refractive index of the $\mathrm{i}$-th layer.

The model is studied with 5, 11 and 21 layers composing the distributed Bragg grating, showing the different response of the sensor. The fiber Bragg grating is constituted by two different dielectric materials chosen in this study with $\mathrm{n}_{\mathrm{h}}=2.32$ and $n_{1}=1.38$ as refractive index, while air and substrate form the core of the sensor outside the FBG with a refractive index of 1 and 1.5 (Figure 3), respectively. The cladding has a refractive index equal to 1.444 . This model is very innovative because the core consists of four different materials.

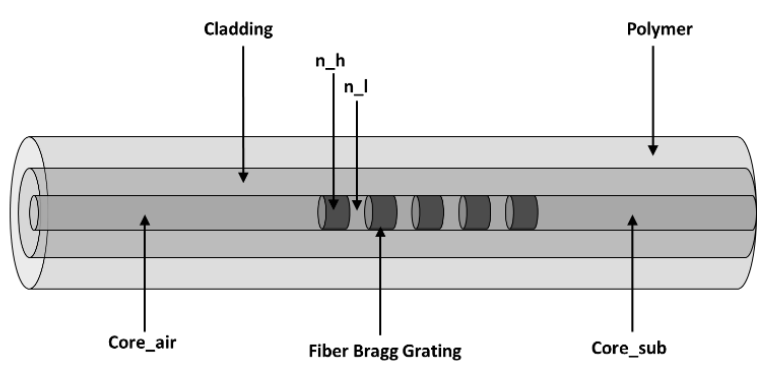

Figure 3. Schematic drawing of polymer-coated fiber Bragg grating $\mathrm{pH}$ sensor. Drawing is not to scale.

The FBG is produced inducing a periodic or aperiodic variation of refractive index in the core, using an ultraviolet source, such as a UV laser [18]. The amount of change depends on the time and intensity of the exposure to UV light [18]. Normally a germanium-doped silica fiber is used in the manufacture of fiber Bragg gratings [18]. The polymer is assumed to coat the sensor for the length of $10 \mathrm{~mm}$. The change in $\mathrm{pH}$ determines a mechanical expansion of the hydrogel that stretches the dimension of the alternating material layers inside the fiber [19], [20]. The change of the layers' thicknesses creates a shift in the Bragg wavelength. The $\mathrm{pH}$ range between 4 and 7.1 is considered to demonstrate the performance of the sensor. The percentage reflectance and the wavelength shift are analysed to provide an estimation of efficiency and sensitivity in the measuring range.
In the study both a 2-D and a 3-D geometry were analysed. The planar technology has been chosen to adapt the FBG to the examined surfaces in the synthesis of the device. In the future physical realization, the cladding material and the Bragg grating will be deposited by using the standard microelectronic processes on two different polymer substrates, making two identical samples. Finally, the two surfaces will be bonded achieving the final structure. External hydrogel is made up of a combination of a solid crosslinked polymeric chain and an adjacent aqueous solution [15]. The $\mathrm{pH}$-sensitive hydrogel will coat the FBG to obtain the final sensor.

Data acquisition will be performed with an optical source, an optical coupler to prevent the reflected light to be propagated back, and an optical spectrum analyser for detecting the sensor response.

\subsection{Materials - sensor variant}

The FBG pH sensor has also been studied with other electromagnetic parameters to allow an easier manufacturability. The fiber Bragg grating is comprised of different dielectric materials compared to the materials for the first sensor of the study; the grating is studied in three configurations with $n_{h}=1.4$ and $n_{l}=1.38, n_{h}=2.2$ and $n_{l}=1.38$, and finally $n_{h}=3$ and $n_{l}=1.38$. The core of the sensor outside the FBG is assumed to have a refractive index of 1.451 [21], which is characteristic of glassy material for the optic frequencies, while the cladding that surrounds the core of the sensor is set to 1.444 [21]. In this scenario the core is made out of three different materials that are realized with a constant UV light through different exposure times. The choice to set the materials of the sensor to be around 1.5 as refractive index is due to manufacturing considerations. Knowing that this last value is typical of the glass, the standard microelectronic processes on two different polymer substrates will be more straightforward to be used. The sensor has a length of $100 \mu \mathrm{m}$. The core of the sensor was set to $6.08 \mu \mathrm{m}$ as diameter, while the cladding was set to $125 \mu \mathrm{m}$ [21].

The Bragg wavelength is considered to be $1550 \mathrm{~nm}$ for this second phase, because at this wavelength the loss of any optical fiber is minimum.

\section{RESULTS}

In order to validate the measurement system, we have conducted simulations with COMSOL Multiphysics (Wave Optics Module), based on the FEM solver. A homemade code in Matlab environment was used for the post processing of the data. The grating period $\Lambda$ is around $158.9 \mathrm{~nm}$ and the Bragg wavelength is around $550 \mathrm{~nm}$.

In Figure 4, the simulation results show an evident shift of the wavelength as a function of $\mathrm{pH}$ variation in a time period of $0.05 \mathrm{~ns}$ [22]. The chart is based on the assumption of having the nominal length of the sensor for a $\mathrm{pH}$ value equal to 4 .

It is observed that the shift in the wavelength presents an increasing behaviour, approximately linear, when the $\mathrm{pH}$ increases from 4 up to 7.1.

As expected, the wavelength shift shown in Figure 4 is identical for the three scenarios with a number of layers of 5 , 11 and 21 for FBG. The shift in the peak of the wavelength is independent from the number of layers in the model. 


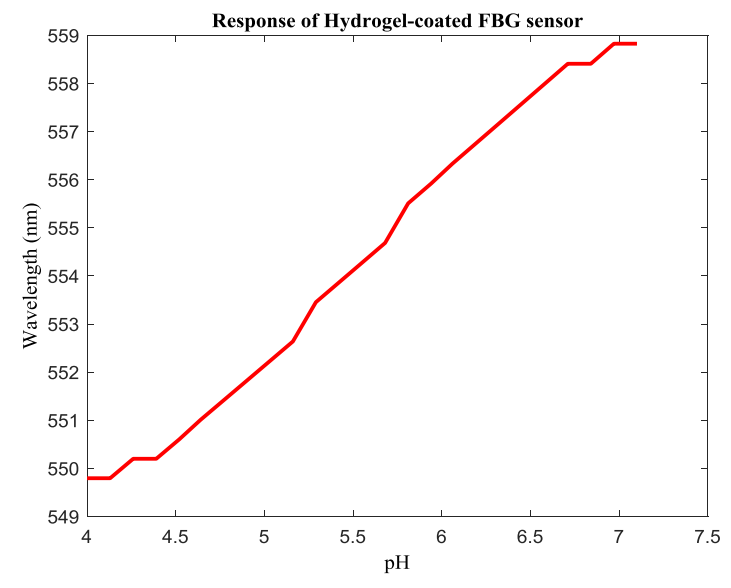

Figure 4. Response of a fiber Bragg grating coated with Hydrogel as a function of $\mathrm{pH}$.

Figure 5 depicts the peak of the percentage reflection in the $\mathrm{pH}$ range 4-7.1. Increasing the number of layers from 5 to 21 results in an increase of the reflectance of the initial light intensity, while maintaining the same pattern. As shown in Figure 5 the reflectance peak of the sensor, when 21 layers are considered, is higher than $99.99 \%$, reaching almost the total reflection.

As depicted in Figure 5, the higher the number of layers in the sensor, the narrower is the range of the reflectance where the peak values fall.
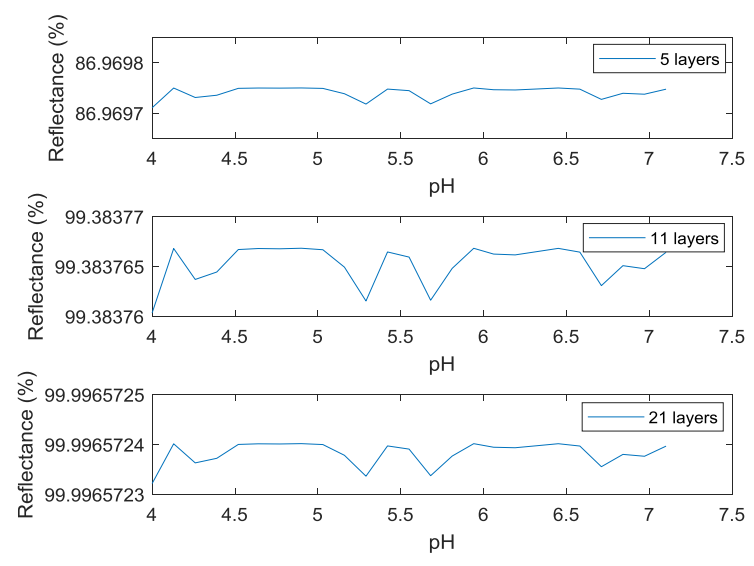

Figure 5. Trend of the peak of percentage reflectance of the distributed Bragg grating in the range of $\mathrm{pH} 4-7.1$ for number of layers 5, 11 and 21.

Figure 6 illustrates that the response of the distributed Bragg grating in the $\mathrm{pH}$ range 4-7.1 shows a narrower reflectance range with a higher number of layers in the FBG for vacuum wavelength. The blue lines in the three charts represent the reflectance for a $\mathrm{pH}$ of 4 , while the red lines represent the reflectance for a $\mathrm{pH}$ of 7.1 . All the curves for the $\mathrm{pH}$ within 4 and 7.1 are not represented for clarity of the chart, but they are in between the blue and red lines.

Figure 7 shows the percentage reflectance of the sensor for the three different layers of grating. For 21 layers, the reflectance is approximately 100 as illustrated in Figure 5. As depicted in Figure 7, the higher the number of layers in the sensor, the closer to $100 \%$ is the reflectance.
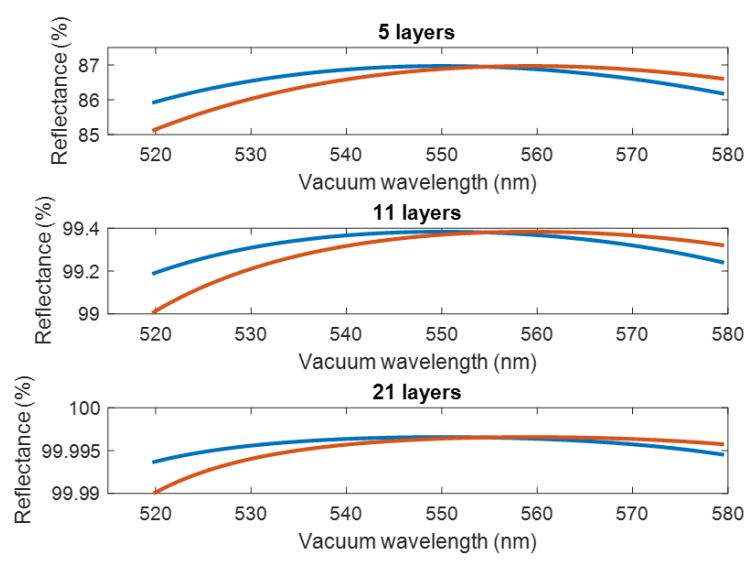

Figure 6. Response of the distributed Bragg grating for all the strains of the hydrogel in the $\mathrm{pH}$ range 4-7.1 for the number of layers 5, 11 and 21 . For clarity, the curves for $\mathrm{pH} 4$ and 7.1, blue and red respectively, are represented; all other curves are in between the two lines.

Concluding, the FBG pH sensor coated with hydrogel has been devised exploiting the hydrogel swelling as a result of the change of surrounding $\mathrm{pH}$ in a time interval and its mechanical effect on the FBG.

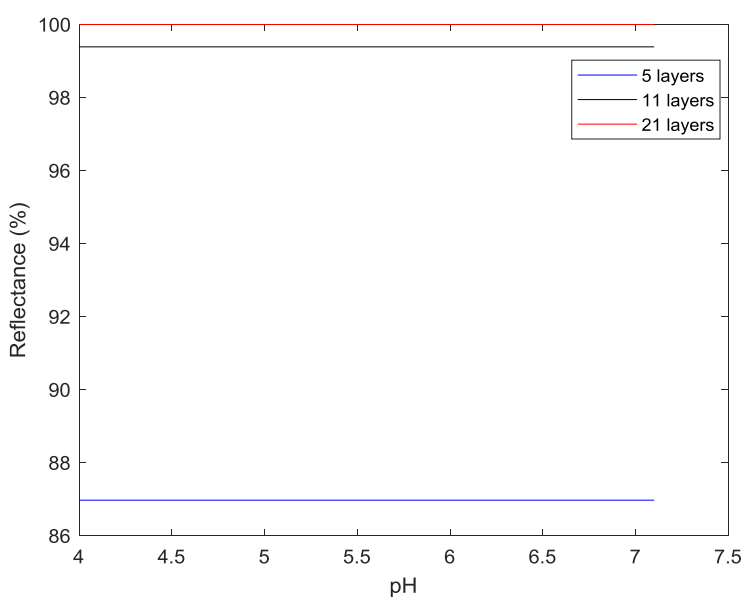

Figure 7. Percentage reflectance of the distributed Bragg grating in the $\mathrm{pH}$ range of 4-7.1 for the number of layers 5,11 and 21 .

\subsection{Results - sensor variant}

In this section the behaviour of the sensor variant, which is made of different materials for the core and the cladding compared to the first one, has been studied. Figure 8 shows the reflectance percentage as a function of the vacuum wavelength in the $\mathrm{pH}$ range 4-7.1 for 5, 11 and 21 layers of the distributed Bragg grating each.

In the Figure 8 the performances of the sensors with different grating materials are compared to one another, for the number of layers of the grating equal to 5,11 and 21 . The $\mathrm{pH}$ values vary from 4 to 7.1 , however only the curves for the limiting $\mathrm{pH}$ values are represented for clarity of the charts. 


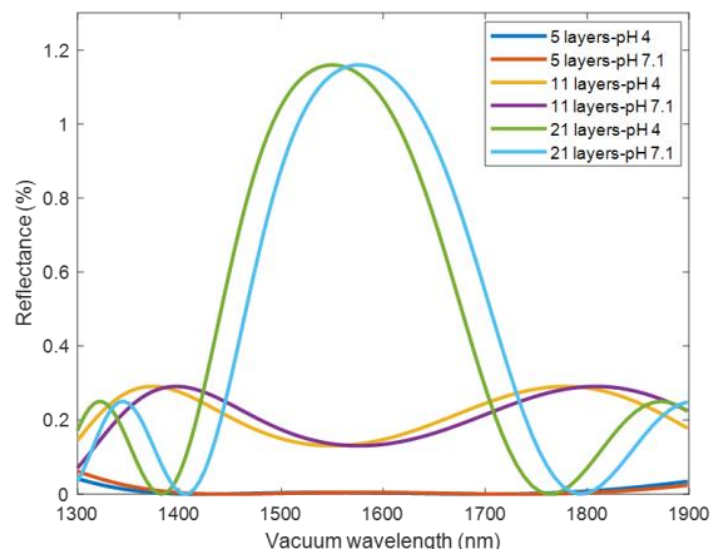

a)

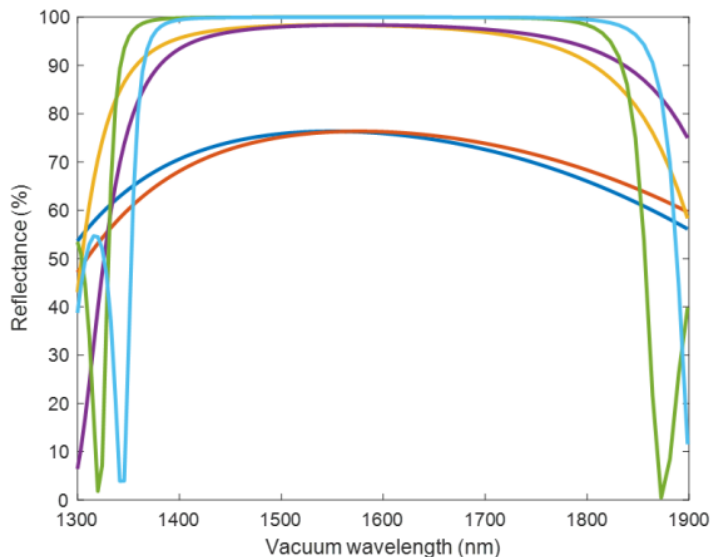

b)

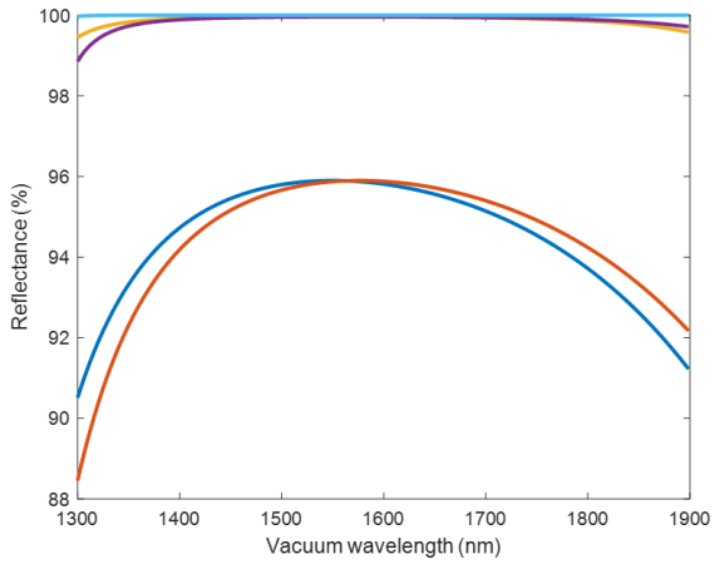

Figure 8. Percentage reflectance of the distributed Bragg grating, with number of layers 5,11 and 21 , as a function of vacuum wavelength between $1300-1900 \mathrm{~nm}$ in the $\mathrm{pH}$ range of 4-7.1. The legend is shown only in the top figure for clarity, but it is also applied to the other two figures. Grating equal to $n_{h}=1.4$ and $n_{1}=1.38(a)$, to $n_{h}=2.2$ and $n_{l}=1.38(b)$, to $n_{h}=3.0$ and $n_{1}=1.38$ (c).

In Figure $8 \mathrm{a}$ ), b) and c) the grating of the sensor is set to $\mathrm{n}_{\mathrm{h}}=1.4$ and $\mathrm{n}_{\mathrm{l}}=1.38, \mathrm{n}_{\mathrm{h}}=2.2$ and $\mathrm{n}_{\mathrm{l}}=1.38$, and $\mathrm{n}_{\mathrm{h}}=3$ and $\mathrm{n}_{1}=1.38$, respectively. In the scenario a) the reflectance peak is narrower for 21 layers compared to scenarios b) and c), with the highest peak in the three figures always being for the 21 layers. In figure 8 a) the percentage reflectance is very low for the three different configurations of grating with 5, 10 and 21 layers, even if the one with 21 shows a slightly higher peak. It is also evident in the three figures that the reflectance for the 21-layer setup is always higher compared to the 5 and 10 ones. From this analysis it can be stated that the higher the number of layers in the grating, the higher the percentage reflectance or peak reflection, as confirmed also with the first sensor studied in the prior section. Moreover, the higher the difference between the refractive index of the two materials that constitute the grating, the higher the peak reflection, even if with a wider bandwidth.

Figure 9 shows the reflectance for the fiber with a number of layers in the grating equal to 21 only, because it is the model that shows the better performances compared to the others. The reflectance peak for the configuration with the grating equal to $\mathrm{n}_{\mathrm{h}}=3$ and $\mathrm{n}_{\mathrm{l}}=1.38$ shows a reflectance power approximately equal to $100 \%$, reaching almost the total reflection in the Bragg bandwidth. The fiber with $\mathrm{n}_{\mathrm{h}}=1.4$ and $\mathrm{n}_{1}=1.38$ shows a very low reflectance, around $1.15965 \%$.
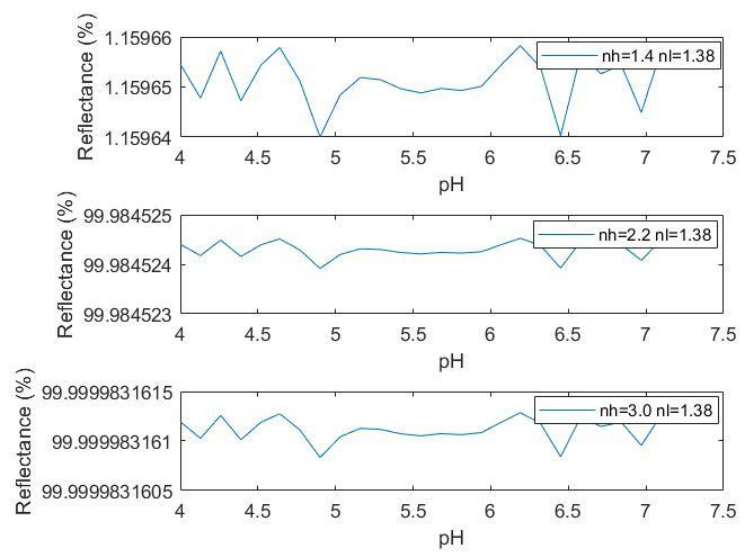

Figure 9. Trend of the peak of percentage reflectance for the distributed Bragg grating in the range of $\mathrm{pH} 4-7.1$ for a grating with 21 layers and refractive index equal to $n_{h}=1.4$ and $n_{l}=1.38, n_{h}=2.2$ and $n_{l}=1.38$, and $n_{h}=3$ and $n_{1}=1.38$, respectively.

In Figure 10 the simulation results show an evident shift of the wavelength as a function of $\mathrm{pH}$ variation in a time period of $0.05 \mathrm{~ns}$. The chart is based on the assumption of having the nominal length of the sensor for a $\mathrm{pH}$ value equal to 4 . It is observed that the shift in the wavelength presents an increasing behaviour, approximately linear, when the $\mathrm{pH}$ increases from 4 up to 7.1 .

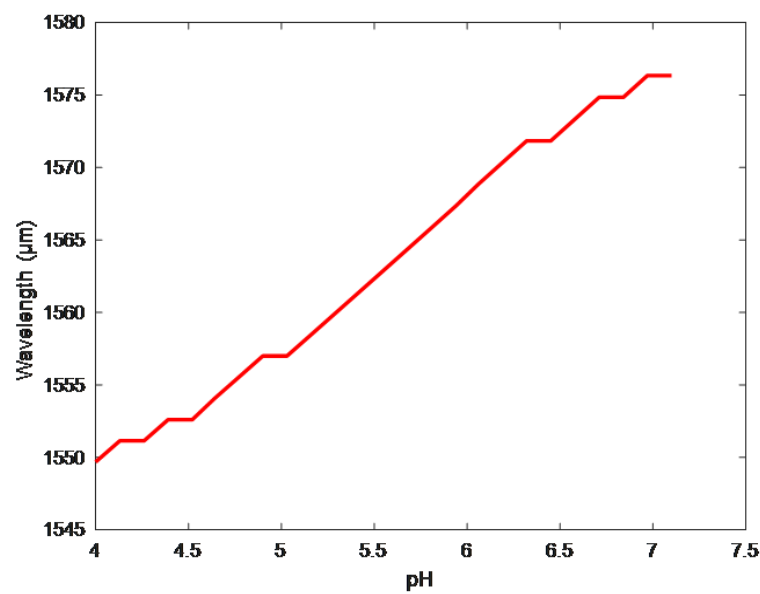

Figure 10. Response of a fiber Bragg grating coated with hydrogel as a function of $\mathrm{pH}$. 
The sensitivity of the sensors for all different configurations with different materials for the grating provided the same response, because the Bragg grating period is a function of the wavelength and refractive index. This fiber, compared to the one with air and substrate in the core outside the grating, shows a higher sensitivity in the spectrum range under analysis, being around $8.58 \mathrm{~nm} / \mathrm{pH}$.

\section{DISCUSSION}

The response of the sensor in Figure 4 shows approximately linear behaviour in the $\mathrm{pH}$ range 4-7.1. Changing the number of layers in the grating does not affect the response of the FBG sensor in terms of wavelength shift, but it has an effect on the reflectance intensity as showed in Figure 5. Subsequently, the sensor was studied with different grating materials for maximizing its performances. In Figure 8 the behaviours of the sensor with different grating materials are compared to one another, $\mathrm{n}_{\mathrm{h}}$ was set equal to 1.4, 2.2 and 3 in three sensor configurations while $\mathrm{n}_{1}$ was kept to 1.38 . From this analysis it was noticed that the higher the number of layers in the grating, the higher the reflectance percentage or peak reflection, and moreover, the higher the difference between the refractive indices of the two materials that constitute the grating, the higher the peak reflection, even if with a wider stop-band. In conclusion, it can be stated that the optimum sensor has the grating constituted by two materials with $n_{1}=1.38$ and $n_{h}$ equal to a value higher than 1.4 and lower than 3 . The purpose is to have the highest sensitivity, thus a high reflectance percentage but also a limited stop-band.

The wavelength drift of the FBG sensor is also induced by bending cross-sensitivity and temperature changes. In this paper these two effects have not been considered. The temperature and strain parameters will be taken into account for the next generation of FBG pH sensors. These will be compensated with either two further FBG sensors or a single FBG sensor able to measure both temperature and strain simultaneously. The dedicated system will be placed in series in the measurement chain. As temperature and strain sensors, FBGs have a fast response time due to their small size and volume. Knowing the real-time outputs of the sensors for the temperature and strain changes, it will be possible to accurately measure the variation of $\mathrm{pH}$ of the material under analysis, subtracting the effect of these two quantities.

Moreover, in future developments this sensor will be integrated with the optical ring resonator in order to improve its performances. Even though the sensor has very small dimensions with a length of $10 \mathrm{~mm}$ for the original configuration and $100 \mu \mathrm{m}$ for its variant, the goal will be to reduce the size even more for medical applications.

\section{CONCLUSION}

In this work, an innovative system has been presented in order to determine the $\mathrm{pH}$ value of the rain. The advantage of forecasting the corrosion of monuments allows optimal restoration programs. These are also depending on the materials under analysis and can have an important impact in terms of cost reductions and higher maintenance efficiency.

An additional advantage, due to the small size of the sensor, is to locate it in modest areas of the artworks without a visual impact. Moreover, the chain of measurement can also be located underground for protecting and conserving the original appearance.
In conclusion, the swelling response of hydrogels to the change of surrounding $\mathrm{pH}$ allowed the development of a model of hydrogel coated FBG pH sensor. Modelling the FBG $\mathrm{pH}$ sensor for monitoring the rain in archaeology and in cultural heritage provided innovative results in terms of high sensitivity and small dimensions of the device, allowing for better intervention planning, especially when used together with other stone conservations [23]. The sensitivity of the first sensor is around $2.91 \mathrm{~nm} / \mathrm{pH}$, as confirmed in Figure 4. A second generation of sensors was developed to facilitate the manufacturability. The analysis of the performances of the sensors showed an even higher sensitivity around $8.58 \mathrm{~nm} / \mathrm{pH}$. The high variation of the refractive index in the model allowed to discover a sensor with a greatly higher sensitivity and better performances. These innovative results can be applied to all other sensors such as strain gauges and thermometers that use the same physical principle.

\section{ACKNOWLEDGEMENT}

The authors wish to thank Samanta F. Strigaro for editing the manuscript. Support was provided solely from institutional department sources.

\section{REFERENCES}

[1] M. Debliquy, J.-M. Renoirt, C. Caucheteur, P. Mégret, M.-G. Olivier, $\mathrm{PH}$ sensor based on tilted fiber Bragg gratings covered by a sol-gel, IMCS 2012 - The 14th International Meeting on Chemical Sensors, Nuremberg, Germany, 2012, pp. 652-654.

[2] R. J. Cheng, J. R. Hwu, J. T. Kim, S. M. Leu, Deterioration of Marble Structures. The Role of Acid Rain, Analytical Chemistry, 59(2), 1987, pp. 104A-106A.

[3] A. Singh, M. Agrawal, Acid rain and its ecological consequences, Journal of Environmental Biology, 29(1), 2008, pp. 15-24.

[4] D. Camuffo, Acid Rain And Deterioration Of Monuments: How Old Is The Phenomenon?, Atmospheric Environment, 26B (2), 1992, pp. 241-247.

[5] J. Marczak, A. Koss, P. Targowski, M. Góra, M. Strzelec, A. Sarzyński, W. Skrzeczanowski, R. Ostrowski, A. Rycyk, Characterization of Laser Cleaning of Artworks, Sensors, 8(10), 200), pp. 6507-6548.

[6] G. E. Likens, F. H. Bormann, N. M. Johnson, Acid Rain, Environ_ment: Science and Policy for Sustainable Development, 14(2), 2008, pp. 33-40.

[7] R. Butlin, Effects of Air Pollutants on Buildings and Materials, Proceedings of the Royal Society of Edinburgh. Section B. Biological Sciences, 97, 1990, pp. 255-272.

[8] S. J. Haneef, J. B. Johnson, C. Dickinson, G. E. Thompson, G. C. Wood, Effect of Dry Deposition of NOx and SO2 Gaseous Pollutants on the Degradation of Calcareous Building Stones, Atmospheric Environment. Part A. General Topics, 26(16), 1992, pp. 2963-2974.

[9] I. Yulianti, A. S. M. Supa'at, S. M. Idrus, N. M. Kassim, A. M. Alhetar, Fiber Bragg grating based $\mathrm{pH}$ sensor, Enabling Science and Nanotechnology (ESciNano), International Conference on, Kuala Lumpur, Malaysia, 2010, pp. 424-428.

[10] I. Yulianti, A.S.M. Supa'at, S.M. Idrus, "Characterization of fiber Bragg grating sensor for $\mathrm{pH}$ measurement," Advanced Intelligent Mechatronics (AIM), IEEE/ASME International Conference on, Besançon, France, (2014), pp. 1163-1166.

[11] V. N. K. Pabbisetti, S. S. Madhuvarasu, Hydrogel-coated fiber Bragg grating sensor for $\mathrm{pH}$ monitoring, Optical Engineering, 55(6), 2015, pp. 066112-066112.

[12] M. F. Jaafar, H. M. Saman, M. N. M. Sidek, Simultaneous monitoring on corrosion-pH-temperature using multiplexed fiber Bragg grating sensors techniques in new RC structure: A 
Review, International Journal of Civil Engineering and GeoEnvironmental, 4, 2013, pp. 41-48.

[13] L. Y. Shao, M. J. Yin, H. Y. Tam, J. Albert, Fiber optic pH sensor with self-assembled polymer multilayer nanocoatings, Sensors, 13, 2013, pp. 1425-1434.

[14] F. Farahi, D. J. Webb, J. D. C. Jones, D. A. Jackson, Simultaneous Measurement of Temperature and Strain: CrossSensitivity Considerations, Journal of Lightwave Technology, 8(2), 1990, pp. 138-142.

[15] I. Yulianti, A. S. M. Supa'at, S. M. Idrus, O. Kurdi, M. R. S. Anwar, Modeling of hydrogel coated fiber Bragg grating $\mathrm{pH}$ sensor, International Journal of Information and Electronics Engineering, 3(3), 2013, pp. 99-103.

[16] T. P. Jones and M. D. Porter, Optical pH sensor based on the chemical modification of a porous polymer film, Analytical Chemistry, 60, 1988, pp. 404-406.

[17] M. J. P. Leiner, P. Hartmann, Theory and practice in optical $\mathrm{pH}$ sensing, Sensors and Actuators B: Chemical, 11, 1993, pp. 281289.

[18] X. Chen, C. Zhang, D. J. Webb, G. D. Peng, K. Kalli, Bragg grating in polymer optical fibre for strain, bend and temperature sensing, Measurement Science and Technology, (21), 2010.
[19] H. Li, Smart Hydrogel Modelling, Springer, Berlin, 2009, 978-4431-54399-2, pp. 9-65.

[20] H. Li, T. Y. Ng, Y. K. Yew, K. Y. Lam, Modeling and simulation of the swelling behavior of $\mathrm{pH}$-stimulus-responsive hydrogels, Biomacromolecules, 6, 2004, pp. 109-120.

[21] X. F. Huang, Z. M. Chen, L. Y. Shao, K. F. Cen, D. R. Sheng, J. Chen, H. Zhou, Design and characteristics of refractive index sensor based on thinned and microstructure fiber Bragg grating, Applied Optics, 47(4), 2008, pp. 504-511.

[22] L. Dinia, F. Mangini, M. Muzi, F. Frezza, Fiber Bragg grating multifunctional $\mathrm{pH}$ sensor for monitoring the rain in cultural heritage, IMEKO International Conference on Metrology for Archaeology and Cultural Heritage Lecce, Italy, 2017, pp. 213 216, ISBN: 978-1-5108-5818-3.

[23] A. Macchia, F. Mangini, S. A. Ruffolo, M. Muzi, L. Rivaroli, M. Ricca, F. Frezza, A novel model to detect the content of inorganic nanoparticles in coatings used for stone protection, Progress in Organic Coatings, Vol. 106, 2017, pp. 177-185. 